\title{
High-Resolution Mass Spectrometric Analysis of Biomass Pyrolysis Vapors
}

\author{
Earl Christensen, Robert J. Evans, and Daniel Carpenter
}

National Renewable Energy Laboratory

15013 Denver West Parkway

Golden, CO 80401-3305 USA

\begin{abstract}
CORRESPONDING AUTHOR: To whom correspondence should be addressed: E-mail: earl.christensen@,nrel.gov; Telephone: 373-275-4496
\end{abstract}

\section{Abstract:}

Vapors generated from the pyrolysis of lignocellulosic biomass are made up of a complex mixture of oxygenated compounds. Direct analysis of these vapors provides insight into the mechanisms of depolymerization of cellulose, hemicellulose, and lignin as well as insight into reactions that may occur during condensation of pyrolysis vapors into bio-oil. Studies utilizing pyrolysis molecular beam mass spectrometry have provided valuable information regarding the chemical composition of pyrolysis vapors. Mass spectrometers generally employed with these instruments have low mass resolution of approximately a mass unit. The presence of chemical species with identical unit mass but differing elemental formulas cannot be resolved with these instruments and are therefore detected as a single ion. In this study we analyzed the pyrolysis vapors of several biomass sources using a high-resolution double focusing mass spectrometer. High-resolution analysis of pyrolysis vapors allowed for speciation of several compounds that 
1 would be detected as a single ion with unit mass resolution. These data not only provide greater

2 detail into the composition of pyrolysis vapors but also highlight differences between vapors

3 generated from multiple biomass feedstocks.

\section{Introduction:}

5 Concerns over environmental impacts of burning fossil carbon and desire for energy security

6 have driven research interest in production of fuels and chemicals from renewable sources.

7 Thermochemical conversion of solid biomass to liquid by fast pyrolysis has potential to produce

8 large volumes of oil that can be used to displace petroleum.[1] Polymeric materials that make up

9 lignocellulosic biomass depolymerize at moderate to high temperatures generating gaseous

10 products as well as char.[2] When cooled, pyrolysis vapors condense into a liquid referred to as

11 bio-oil. This oil is vastly different in composition from petroleum as it has high oxygen content

12 and is a mixture of carboxylic acids, phenolics, anhydrosugars, numerous oxygenates, and

13 water.[3] Pyrolysis bio-oil is not desirable as a fuel for most applications due to low energy

14 density, high acidity, and low stability; however, catalytic deoxygenation can be used to convert

15 bio-oil into hydrocarbons that can supplement petroleum.[4]

16 Process and catalyst designs for removing oxygen by catalytic upgrading of pyrolysis vapors can

17 possibly be improved with knowledge of the primary pathways of pyrolysis as well as

18 composition of pyrolysis products. Mass spectrometry is well suited for the analysis of pyrolysis

19 vapors due to nearly universal detection of gaseous compounds and the ability to identify

20 unknowns. The primary products from pyrolysis of biomass have been elucidated using such

21 techniques as pyrolysis gas chromatography with mass spectrometry (GC-MS)[5,6], molecular

22 beam mass spectrometry (MBMS)[7], and in-source pyrolysis.[8] Analysis of pyrolysis vapors

23 by GC-MS provides both qualitative identifications of compounds from characteristic 
1 fragmentation patterns as well as quantitative data when standards are available for instrument

2 calibration. In addition to identifying primary products, pyrolysis GC units have been designed

3 with micro reactors to evaluate catalytic conversion of oxygenated compounds to

4 hydrocarbons.[9-11] Gas chromatography columns are limited in temperature requiring lower

5 temperatures than are applied for pyrolysis, potentially allowing for condensation or reactions

6 between pyrolysis vapor compounds prior to analysis. MBMS provides rapid analysis of vapors

7 and can be applied in process relevant conditions. Unlike GC-MS, an MBMS instrument does

8 not utilize chromatography to separate individual components prior to introduction into the

9 ionization source, but ionizes the entire gas sample simultaneously, allowing for very rapid data

10 collection. Deconvolution of mass spectra from ionization of multiple compounds is facilitated

11 by application of lower ionization energy than is typically applied with GC-MS systems to

12 minimize fragmentation of molecular ions.[12] Assigning compounds based on mass does not

13 provide structural information and there can be significant ambiguity with low resolution mass

14 spectrometers typically used with MBMS systems. As an example, carbon dioxide $\left(\mathrm{CO}_{2}\right)$ and

15 acetaldehyde $\left(\mathrm{C}_{2} \mathrm{H}_{4} \mathrm{O}\right)$ are both nominally $44 \mathrm{Da}$ and their molecular ions are indistinguishable

16 with unit-mass resolution of a single quadrupole mass filter. However, the monoisotopic masses

17 of carbon dioxide and acetaldehyde are 43.990 $\mathrm{Da}$ and 44.026 $\mathrm{Da}$, respectively. This difference

18 of $0.036 \mathrm{Da}$ can be distinguished with high-resolution mass spectrometry such as time-of-flight

19 or double focusing mass filters. In a recent study an ultrahigh-resolution Fourier transform ion

20 cyclotron resonance mass spectrometer coupled with thermogravimetry was utilized to identify

21 molecular formulae of thermal degradation components from biomass from exact mass

22 measurements.[13] With sufficient mass resolution, multiple compounds can be identified within

23 a fraction of a mass unit and compound assignments can be made with greater confidence. 
1 In this study we explore the application of a high-resolution mass spectrometer (HRMS) with in-

2 source pyrolysis MS for analysis of pyrolysis vapors from six sources of biomass. Analysis of

3 primary pyrolysis products using this methodology was focused on determining whether multiple

4 compounds could be detected within a single mass unit as well as how these compounds may

5 differ between biomass feedstocks.

6 Methods and Materials:

$7 \quad$ Biomass Feedstocks

8 Biomass samples included aspen, corn stover, oak, pine, switchgrass, and a 50:50 blend of pine

9 and switchgrass. Biomass was knife milled using a $1 / 8$ " screen and sieved to a $<0.5 \mathrm{~mm}$ size

10 fraction. The carbon, hydrogen, and nitrogen contents of each feedstock were measured using a

11 LECO TruSpec CHN+S module. Proximate analysis was conducted with a LECO TGA701

12 thermogravimetric analyzer, following ASTM Method D5142. Compositional analysis (lignin,

13 cellulose, hemicellulose) was performed using the standard Laboratory Analytical Procedures for

14 Biomass Compositional Analysis.[14] The results of the biomass solids analyses are summarized

15 in Table 1.

16

17 Table 1. Proximate, ultimate, and compositional analyses of biomass feedstocks.

\begin{tabular}{|c|c|c|c|c|c|}
\hline & Aspen & Pine & Oak & Switchgrass & Corn Stover \\
\hline \multicolumn{6}{|c|}{ Proximate analysis (wt\%, as received) } \\
\hline Moisture & 2.89 & 3.08 & 3.04 & 3.71 & 6.90 \\
\hline Volatile matter & 92.78 & 87.29 & 86.54 & 80.90 & 79.82 \\
\hline Fixed carbon & 4.11 & 9.30 & 10.20 & 9.54 & 6.11 \\
\hline Ash & 0.21 & 0.32 & 0.23 & 5.84 & 7.16 \\
\hline \multicolumn{6}{|c|}{ Ultimate analysis (wt\%, as received) } \\
\hline Carbon & 47.33 & 48.35 & 47.59 & 44.15 & 39.52 \\
\hline Hydrogen & 7.13 & 6.70 & 5.89 & 6.09 & 6.16 \\
\hline Nitrogen & 0.04 & 0.06 & 0.07 & 0.56 & 0.80 \\
\hline Oxygen (by difference) & 45.50 & 44.89 & 46.45 & 49.20 & 53.52 \\
\hline \multicolumn{6}{|c|}{ Compositional analysis (wt\%, as received) } \\
\hline Lignin & 28.81 & 34.37 & 32.25 & 19.86 & 16.56 \\
\hline Cellulose & 39.69 & 38.13 & 38.22 & 33.55 & 34.85 \\
\hline
\end{tabular}


$\underline{\text { Mass Spectrometer }}$

3 Biomass samples were analyzed using a JEOL GCmate II double-focusing mass spectrometer

4 (JEOL, Peabody, MA) equipped with a direct insertion probe (DIP) for in-source pyrolysis MS.

5 The ionization source was operated in electron ionization (EI) mode. The DIP heating element

6 has a maximum heating rate of $4.2^{\circ} \mathrm{C} / \mathrm{sec}$ and a maximum temperature of $500{ }^{\circ} \mathrm{C}$. While this is

7 much slower than fast pyrolysis $\left(\sim 1,000^{\circ} \mathrm{C} / \mathrm{sec}\right)$, it is nonetheless useful for generation of thermal

8 degradation products within the ion source. The mass spectrometer was tuned prior to

9 experiments to a resolving power of $\geq 6,000$ (full width at half maximum (FWHM)) based on

$10 \mathrm{~m} / \mathrm{z} 69$ using the spectrum of perfluorokerosene. The full spectrum of perfluorkerosene was used

11 for mass calibration across the range of the spectrum collected from m/z 10 to 400. Mass spectra

12 were collected for each biomass sample by introducing approximately $1 \mathrm{mg}$ into the ion source

13 and the DIP temperature was ramped from $75^{\circ} \mathrm{C}$ to $500^{\circ} \mathrm{C}$ at the maximum heating rate. Each

14 biomass sample was analyzed in triplicate. Mass spectra of pyrolysis vapors were collected at 15

$15 \mathrm{eV}$ to minimize ion fragmentation while maintaining adequate signal. Potential for ion

16 fragmentation at $15 \mathrm{eV}$ was assessed with model compounds. Quartz wool was saturated with

17 neat standards and introduced into the HRMS in the same manner as with biomass samples.

18 Results:

\section{Model Compound Analysis}

20 Ion fragmentation at $15 \mathrm{eV}$ was assessed by analyzing acetic acid and m-cresol as model

21 pyrolysis vapor compounds (Figure 1). The monoisotopic mass of acetic acid, 60.021 Da, was 
1 detected as the base peak in this spectrum. Fragment ions were detected at $\mathrm{m} / \mathrm{z}=42.013,43.021$,

2 and 45.000, which are consistent with loss of $-\mathrm{OH}_{2},-\mathrm{OH}$ and $-\mathrm{CH}_{3}$, respectively. The $[\mathrm{M}+1]^{+}$

3 ion was detected at $\mathrm{m} / \mathrm{z}=61.028$. Note that the abundance of the $[\mathrm{M}+1]^{+}$ion detected in this

4 spectrum is higher than would be expected from ${ }^{13} \mathrm{C}$ abundance, thus it is likely this ion is also

5 due to $[\mathrm{M}+\mathrm{H}]^{+}$. Resolution of the $[\mathrm{M}+1]^{+}$and $[\mathrm{M}+\mathrm{H}]^{+}$ions is beyond the resolving power of this

6 mass spectrometer (minimum of $\sim 14,000 \mathrm{~m} / \Delta \mathrm{m}$ ) which results in detection of a single ion at

7 nominal $\mathrm{m} / \mathrm{z}=61$. The spectrum of $\mathrm{m}$-cresol shows a base peak at $\mathrm{m} / \mathrm{z}=108.058$, the

8 monoisotopic mass of this compound. Lower abundance ions are also detected at $\mathrm{m} / \mathrm{z}=107.048$

9 and 109.059, which are consistent with $[\mathrm{M}-\mathrm{H}]^{+}$and $[\mathrm{M}+1]^{+}$, respectively. The abundances of

10 fragment ions are considerably reduced compared to ionization at higher ionization potential

11 such as $70 \mathrm{eV}$ used for GC-MS (shown in Figure 1).

12
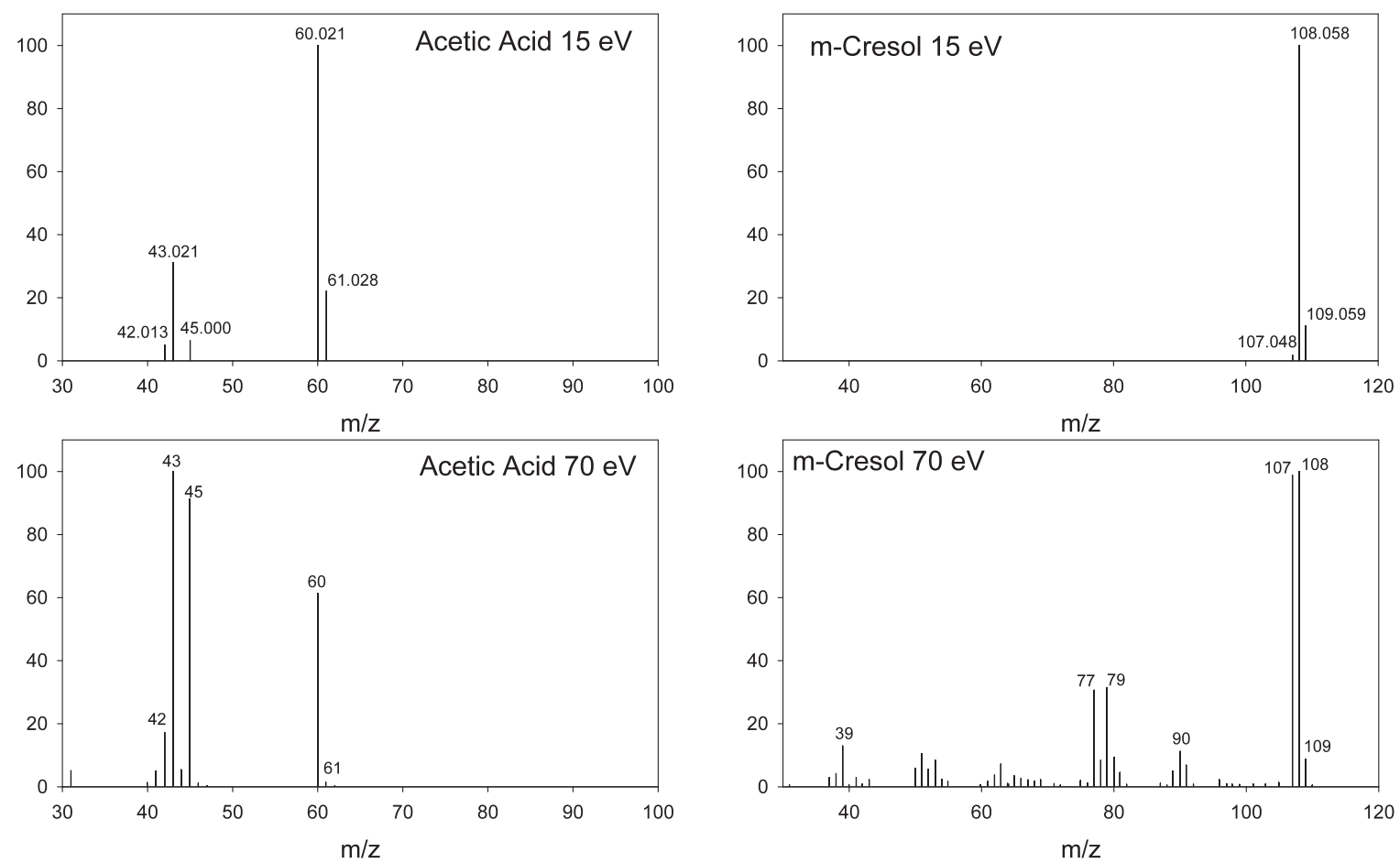

Figure 1. Mass spectra of acetic acid and m-cresol collected at $15 \mathrm{eV}$ with DIP MS compared to 15 fragmentation observed at $70 \mathrm{eV}$ by GC-MS. 
2 Analysis of pyrolysis vapors with the DIP MS instrument was initially assessed with aspen

3 biomass. The MS total ion current (TIC) generated from pyrolysis of this sample produced two

4 peaks during the heating ramp (Figure 2). The predominant ion in the first peak was $\mathrm{m} / \mathrm{z}=$

5210.090 , which is tentatively assigned to a molecular formula of $\mathrm{C}_{11} \mathrm{H}_{14} \mathrm{O}_{4}$ based on proximity to

6 this monoisotopic mass of 210.089 Da. Compound structure cannot be established from mass;

7 however this ion may be attributable to sinapyl alcohol which is a common product of hardwood

8 lignin pyrolysis. The predominant ion in the second peak was $\mathrm{m} / \mathrm{z}=126.030$, tentatively

9 assigned to $\mathrm{C}_{6} \mathrm{H}_{6} \mathrm{O}_{3}(126.032 \mathrm{Da})$. This ion may be due to the presence of 5 -

10 hydroxymethylfurfural, levoglucosenone, or maltol, which are common pyrolysis products of

11 cellulose. The first peak being due to lignin depolymerization while the second peak due to

12 cellulose is expected given that part of lignin decomposes between $200-350{ }^{\circ} \mathrm{C}$, while cellulose

13 decomposes between $300-430{ }^{\circ} \mathrm{C} .[1]$

14

15

16

17

18

19

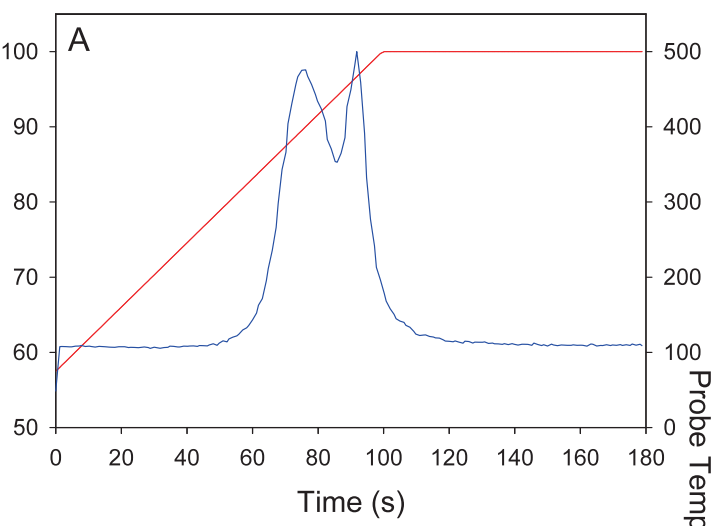

Figure 2. A: Total ion current (TIC) and temperature profile for aspen biomass analyzed with direct insertion probe. B: Primary ion profile during heating. Temperature ramp from $75^{\circ} \mathrm{C}$ to $500^{\circ} \mathrm{C}$ at a rate of $4.2^{\circ} \mathrm{C} / \mathrm{second}$.

$\underline{\text { Feedstock Comparison }}$

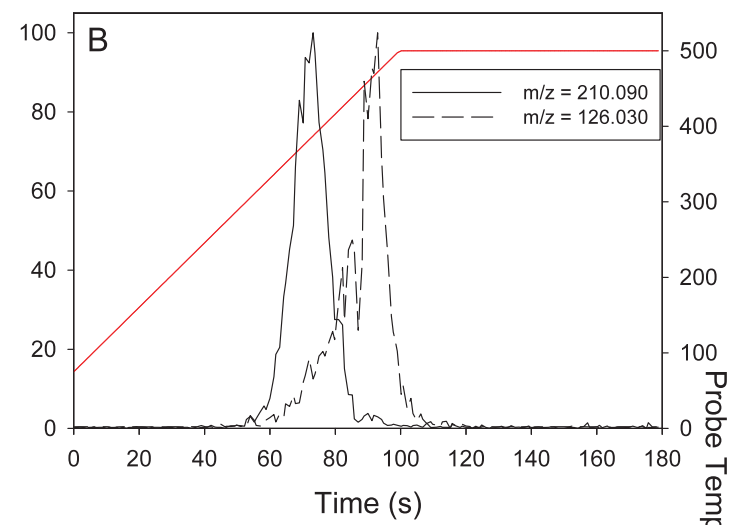


1 Mass spectra collected during pyrolysis of each feedstock were averaged and background

2 subtracted. Resulting spectra for each biomass type are provided in Figure 3. These spectra are

3 similar to those obtained by MBMS.[7] Some of the most abundant ions are listed in Table 2

4 along with assigned formulas. Formulas were assigned from comparison of measured $\mathrm{m} / \mathrm{z}$ to the

5 monoisotopic mass of compounds previously reported in pyrolysis vapor or liquid. [5,7,8,15-25]

6 Mass comparisons were made within a tolerance of 0.005 Da using Mass Mountaineer mass

7 spectra interpretation software (RBC Software, Peabody, MA). These matches are based solely

8 on mass, with no structural information, and therefore other structures cannot be ruled out for

9 these ions. The ions detected include some higher molecular weight compounds which can be

10 attributed to dimers of guaiacol and syringol. Specifically, the ions at m/z 272, 302, and 332 are

11 consistent with the monoisotopic masses of G-G dimer, G-S dimer, and S-S dimer,

12 respectively.[8,25]
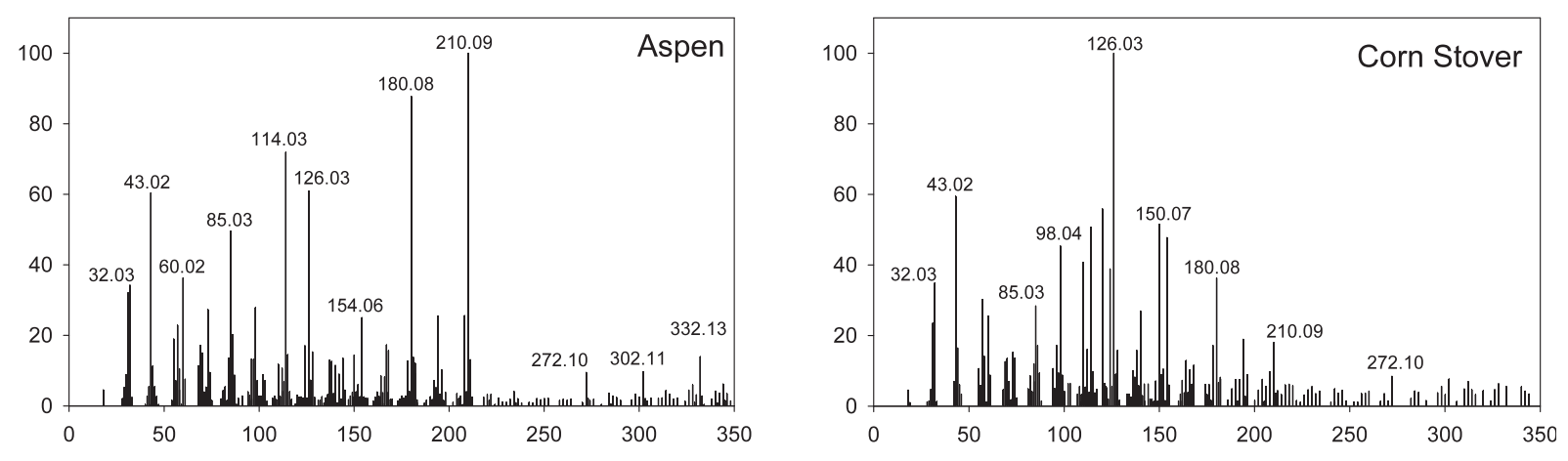

13
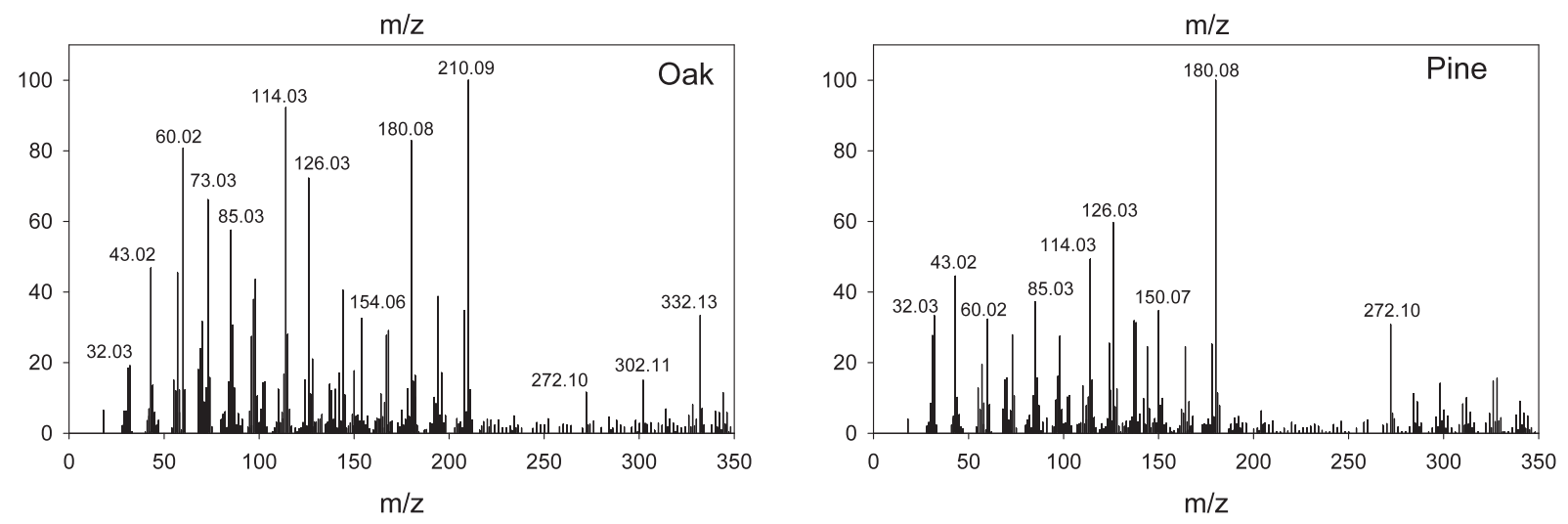

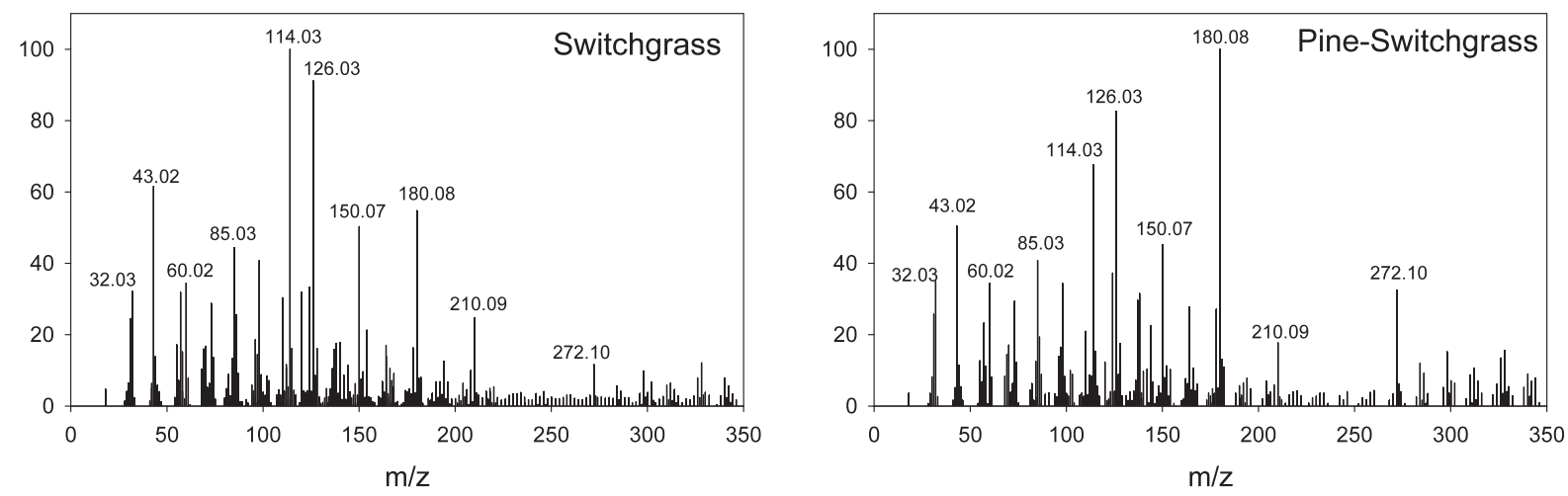

Figure 3. Average mass spectrum of each feedstock

Table 2: Tentative molecular formulas of prominent ions common to the mass spectra of biomass feedstocks. Identifications are based on comparison of detected $\mathrm{m} / \mathrm{z}$ to monoisotopic masses of compounds commonly found in pyrolysis vapor and liquids.

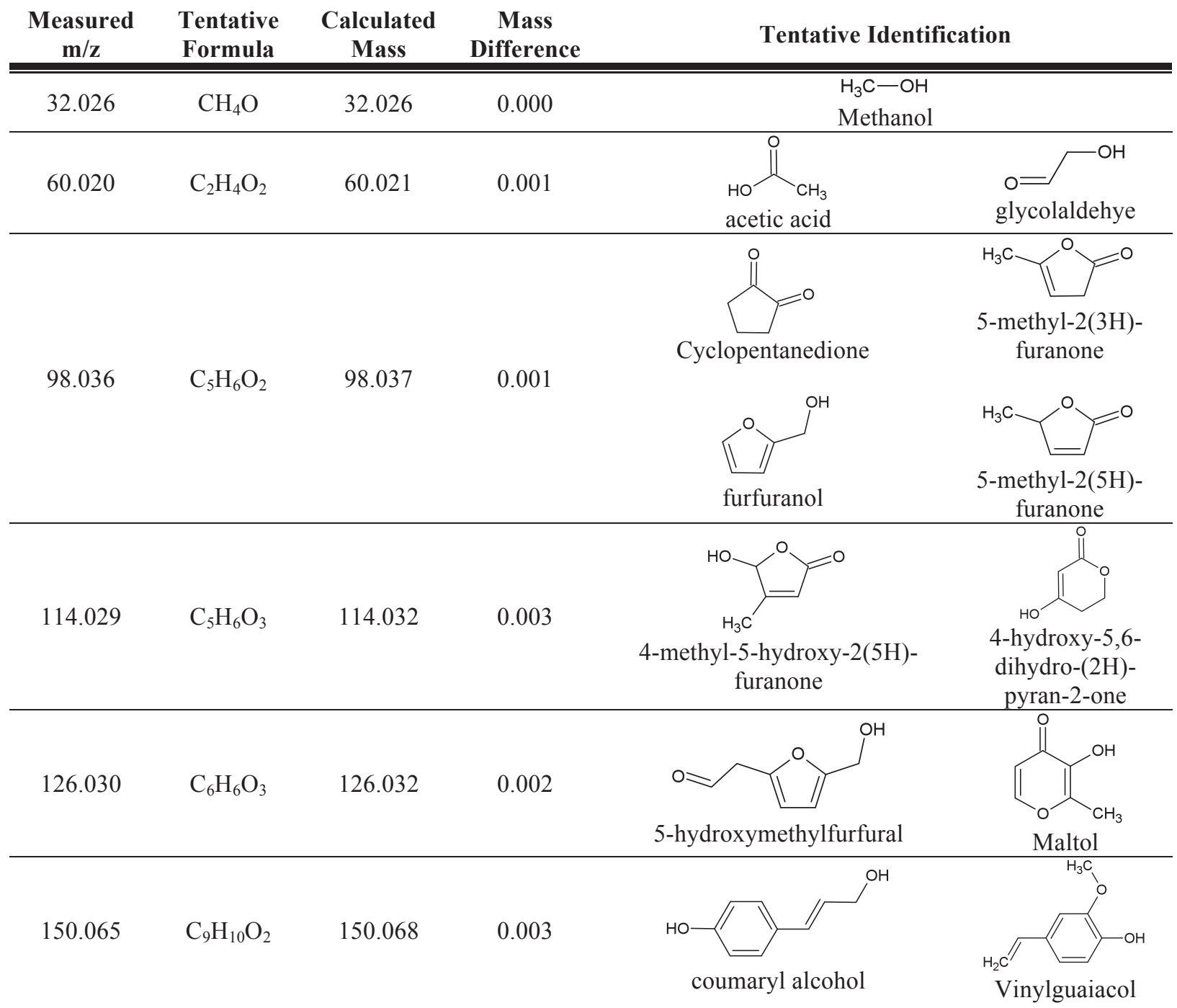




\begin{tabular}{|c|c|c|c|c|}
\hline 154.060 & $\mathrm{C}_{8} \mathrm{H}_{10} \mathrm{O}_{3}$ & 154.063 & 0.003 & Syringol \\
\hline 180.081 & $\mathrm{C}_{10} \mathrm{H}_{12} \mathrm{O}_{3}$ & 180.079 & -0.002 & $\begin{array}{l}{ }_{\mathrm{CH}} \\
\text { coniferyl alcohol }\end{array}$ \\
\hline 210.090 & $\mathrm{C}_{11} \mathrm{H}_{14} \mathrm{O}_{4}$ & 210.089 & -0.001 & $\begin{array}{l}\mathrm{CH}_{3} \\
\quad \text { sinapyl alcohol }\end{array}$ \\
\hline 272.104 & $\mathrm{C}_{16} \mathrm{H}_{16} \mathrm{O}_{4}$ & 272.105 & ( & 4,4'-dihydroxy-3,3'-dimethoxystilbene (G-G dimer) \\
\hline 302.114 & $\mathrm{C}_{17} \mathrm{H}_{18} \mathrm{O}_{5}$ & 302.115 & 0.001 & 4,4'-dihydroxy-3,3',5-trimethoxystilbene (G-S dimer) \\
\hline 332.125 & $\mathrm{C}_{15} \mathrm{H}_{24} \mathrm{O}_{8}$ & 332.126 & -0.001 & 4,4'-dihydroxy-3,3',5,5'-tetramethoxystilbene (S-S \\
\hline
\end{tabular}

3 Close inspection of these mass spectra revealed several ions that had been resolved within one 4 mass unit. Table 3 lists pairs of ions along with potential formulas and identifications. In each 5 case, the pairs of ions differ by approximately $0.036 \mathrm{Da}$, the difference in mass between a single 6 oxygen and $\mathrm{CH}_{4}$. The resolving power of this mass spectrometer is capable of resolving this 7 mass difference up to a molecular weight of $\sim 220 \mathrm{Da}$, above which a higher resolution 
1 instrument would be required to detect two ions if this pattern continues at higher molecular

2 weight.

3 Table 3: Example pyrolysis vapor compounds observed at identical unit mass and differentiated 4 by high-resolution mass spectrometry. Tentative identifications are based on comparison of 5 detected $\mathrm{m} / \mathrm{z}$ to monoisotopic masses of compounds commonly found in pyrolysis vapor and 6 liquids.

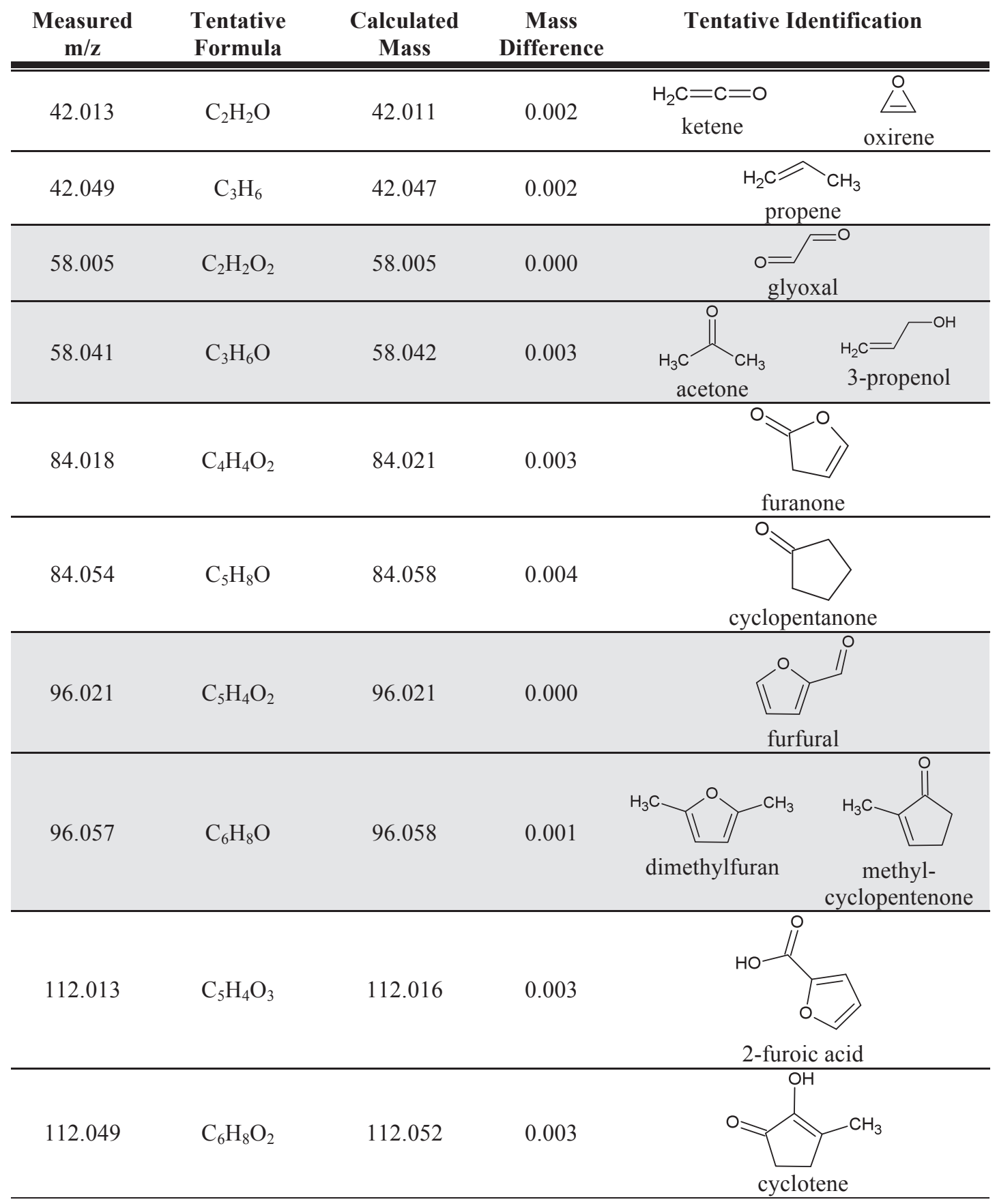




\begin{tabular}{|c|c|c|c|c|}
\hline 138.031 & $\mathrm{C}_{7} \mathrm{H}_{6} \mathrm{O}_{3}$ & 138.032 & 0.001 & $\begin{array}{l}\text { ho } \\
\text { hydroxybenzoic acid }\end{array}$ \\
\hline 138.066 & $\mathrm{C}_{8} \mathrm{H}_{10} \mathrm{O}_{2}$ & 138.068 & 0.002 & $\begin{array}{l}\mathrm{CH}_{3} \mathrm{C}_{3} \\
\text { methylguaiacol }\end{array}$ \\
\hline 152.045 & $\mathrm{C}_{8} \mathrm{H}_{8} \mathrm{O}_{3}$ & 152.047 & 0.002 & $\begin{array}{l}\mathrm{H}_{3} \mathrm{C} \\
\text { vanillin }\end{array}$ \\
\hline 152.079 & $\mathrm{C}_{9} \mathrm{H}_{12} \mathrm{O}_{2}$ & 152.084 & 0.005 & $\begin{array}{c}\mathrm{H}_{3} \mathrm{C}^{\prime} \\
\text { ethylguaiacol }\end{array}$ \\
\hline 164.045 & $\mathrm{C}_{9} \mathrm{H}_{8} \mathrm{O}_{3}$ & 164.047 & 0.002 & coumaric acid \\
\hline 164.079 & $\mathrm{C}_{10} \mathrm{H}_{12} \mathrm{O}_{2}$ & 164.084 & 0.005 & isoeugenol \\
\hline 168.041 & $\mathrm{C}_{8} \mathrm{H}_{8} \mathrm{O}_{4}$ & 168.042 & 0.001 & $\stackrel{\mathrm{O}_{\mathrm{CH}_{3}}}{\text { vanillic acid }}$ \\
\hline 168.074 & $\mathrm{C}_{9} \mathrm{H}_{12} \mathrm{O}_{3}$ & 168.079 & 0.005 & 4-methylsyringol \\
\hline
\end{tabular}

2 Despite this limitation in resolution at higher molecular weights, several interesting pairs of ions

3 are provided in Table 3. Relative abundances of the compounds listed in Table 3 were assessed

4 based on their percent of total ion intensity to provide a comparison of biomass feedstocks

5 (Figure 4). An interesting outcome of these measurements is the detection of compounds which 
1 appear to be uniquely present or absent from particular feedstocks. For instance, at nominal m/z

2138 both m/z 138.032 (hydroxybenzoic acid), and m/z 138.068 (4-methylguaiacol) are detected

3 in all feedstocks with the exception of pine and the pine-switchgrass blend. Further study will be

4 necessary determine potential implications of these differences on pyrolysis pathways and

$5 \quad$ upgrading strategies. 

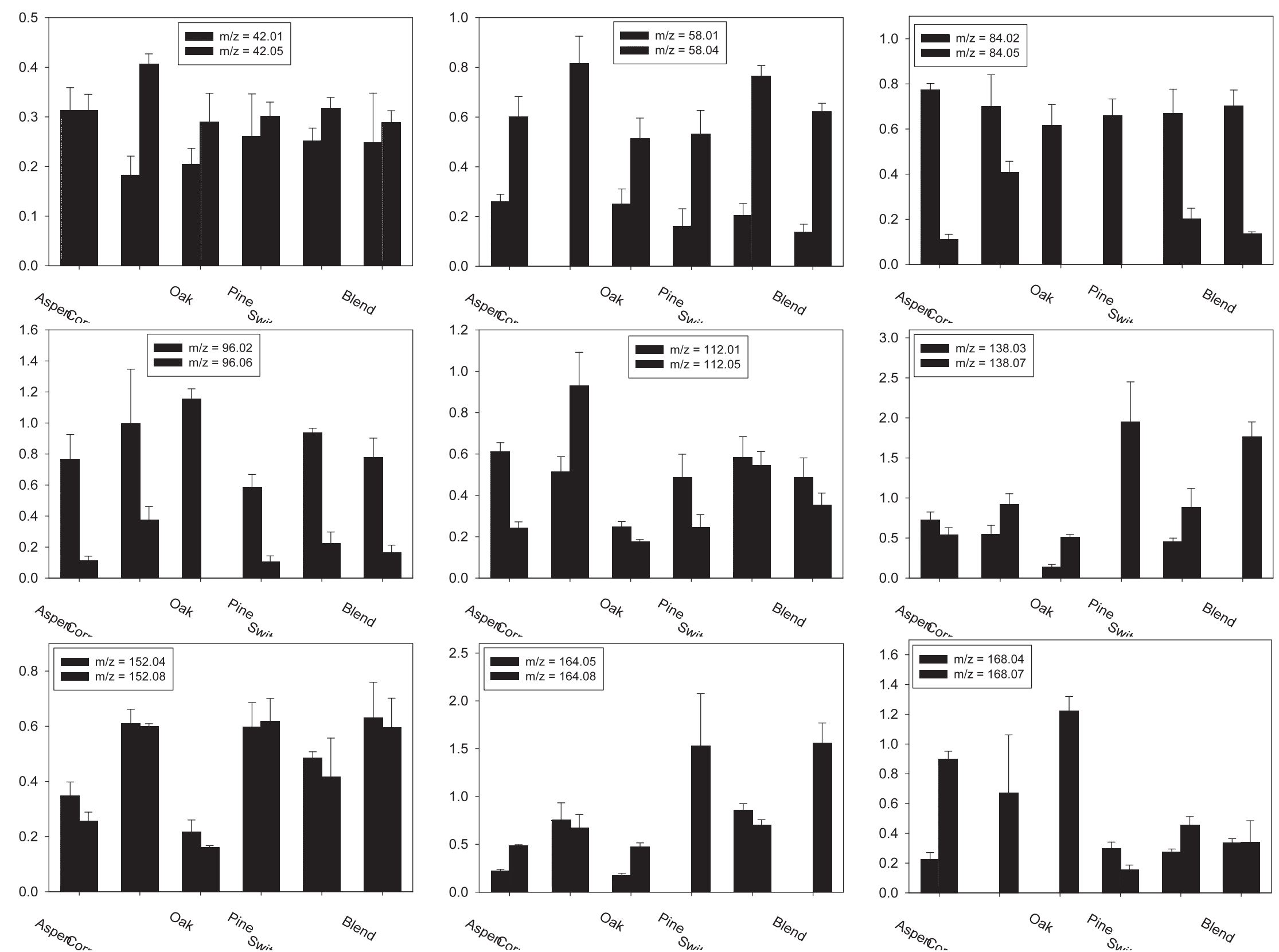

Figure 4. Comparison of abundance of ions present within a single mass unit in the vapor produced by each feedstock. Error bars represent two standard deviations of $\%$ total intensity from triplicate analyses. 
1 Replicate spectra were compared by principal component analysis (PCA) to assess the capability

2 of this methodology to differentiate feedstocks. Resultant scores and loadings of the PCA are

3 provided in Figure 5. The mass spectra of individual feedstocks are fully differentiated by PCA.

4 The hardwoods are separated from the other feedstocks by the first component primarily due to

5 syringyl lignin constituents. The loadings of PC-1 show the importance of sinapyl alcohol (m/z

6210.09 in differentiating the oak and aspen from the pine and grasses. PC-2 shows the grasses are

7 separated from the hard and softwoods due to the abundance of $\mathrm{m} / \mathrm{z} 126.03,110.03,120.06$ and

$8 \quad 150.07$ in switchgrass and corn stover. This is likely due to the abundance of 5-

9 hydroxymethylfurfural, 5-methylfurfural in these spectra relative to the woods given their lower

10 lignin content, and p-vinylphenol and p-coumaryl alcohol from coumaryl lignin abundance of

11 the grasses. The pine-switchgrass blend falls very close to the pine sample. This could be due an

12 increased sensitivity to low-eV electron ionization of the aromatic lignin products, which are

13 expected to be more prominent in pine pyrolysis vapors.
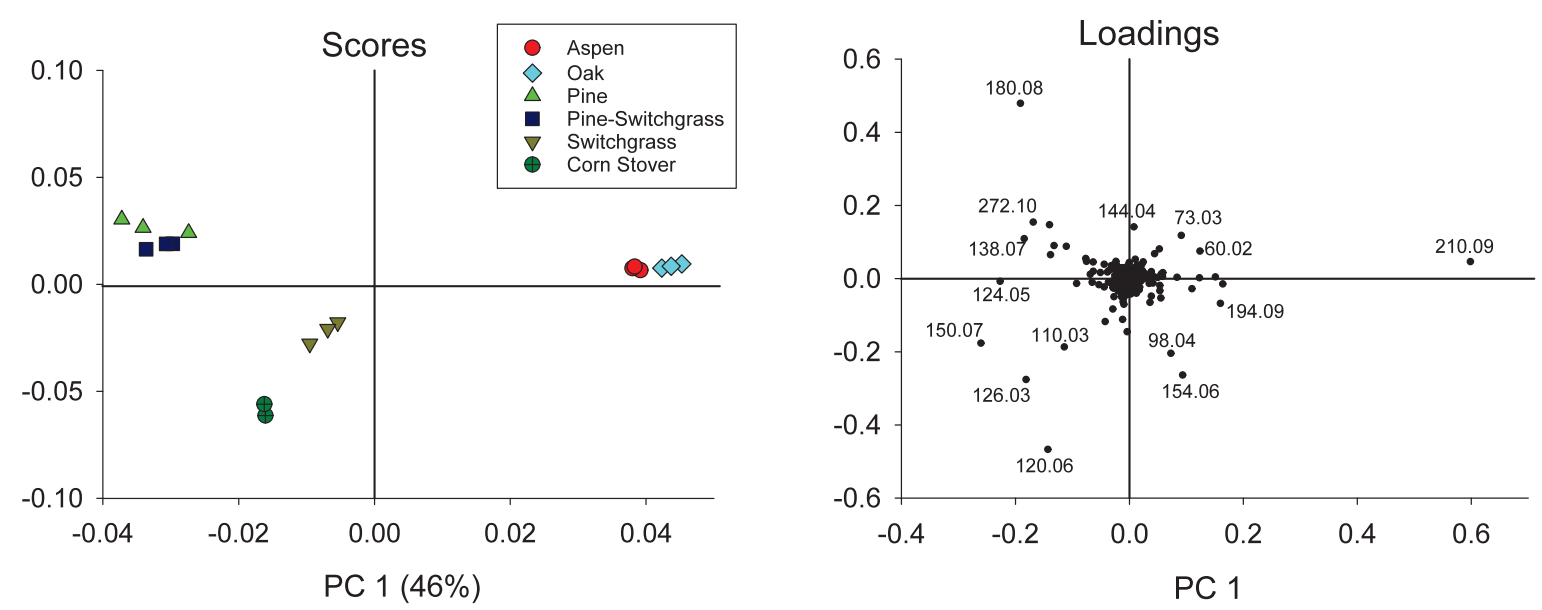

14

15

16

Fig. 5: Principal component analysis of mass spectra of individual feedstocks. 
1 High resolution mass spectrometry was used to differentiate compounds of identical nominal

2 mass present in pyrolysis vapor. Enhanced molecular detail provided for different feedstocks

3 could have important mechanistic implications, both for a better understanding of primary

4 pyrolysis pathways, and for understanding how changes occur as products are condensed and

5 stored. For example, although ketene is a permanent gas, it is highly reactive and could be an

6 important factor in the cross-linking of other bio-oil constituents, leading to an increase in the

7 molecular weight of the bio-oil. Moreover, ketene may go undetected in routine analytical

8 systems since it would not necessarily be reported by on-line gas chromatography, for instance.

9 In addition, as pyrolysis processes are developed and additional biomass resources are

10 considered, special attention needs to be paid to mechanisms of oxygen rejection and hydrogen

11 retention in the liquid products. The high proportion of dimethylfuran or methyl cyclopentenone

$12\left(\mathrm{C}_{6} \mathrm{H}_{8} \mathrm{O}\right)$ in oak, switchgrass, and corn stover is interesting given it is relatively deoxygenated

13 product (17\% oxygen).

14 The methodology utilized in this study is not capable of rapid heating and is therefore not a true

15 representation of fast pyrolysis. The coupling of a fast pyrolysis micro-reactor such as those used

16 in lower-resolution MS studies [26-28] with a higher-resolution mass spectrometer would

17 provide greater insight into primary fast pyrolysis compounds and mechanisms. The use of a

18 direct insertion probe is highly limited in throughput which could also be improved with an

19 automated fast pyrolysis sampling unit such as those used with GC-MS.[9-11] In addition the

20 application of MS x MS would provide structural information and allow for confident compound

21 assignments. Despite these drawbacks of the instrumentation utilized the results show that

22 inclusion of higher resolution mass spectrometers could greatly enhance the level of detail in 
1 data generated during pyrolysis experiments. Development of higher resolution MBMS

2 techniques would greatly increase understanding of the primary components of pyrolysis vapor.

\section{Acknowledgments:}

4 This work was supported by the Bioenergy Technologies Office (BETO) at the U.S. Department

5 of Energy's Office of Energy Efficiency and Renewable Energy under Contract no. DE-AC36-

6 08-GO28308 with the National Renewable Energy Laboratory.

\section{References:}

8 [1] D. Carpenter, T.L. Westover, S. Czernik, W. Jablonski, Biomass feedstocks for renewable

[6] P.R. Patwardhan, R.C. Brown, B.H. Shanks, Understanding the fast pyrolysis of lignin, fuel production: a review of the impacts of feedstock and pretreatment on the yield and product distribution of fast pyrolysis bio-oils and vapors, Green Chem. 16 (2014) 384406. doi:10.1039/C3GC41631C.

[2] T.V. Bridgwater, G.V.C. Peacocke, Fast Pyrolysis for Biomass, Renew. Sustain. Energy Rev. 4 (2000) 1-73.

[3] D. Mohan, C.U. Pittman, P.H. Steele, Pyrolysis of wood/biomass for bio-oil: A critical review, Energy and Fuels. 20 (2006) 848-889. doi:10.1021/ef0502397.

[4] D.C. Elliott, Historical developments in hydroprocessing bio-oils, Energy and Fuels. 21 (2007) 1492-1815. doi:10.1021/ef070044u.

[5] P.R. Patwardhan, J. a. Satrio, R.C. Brown, B.H. Shanks, Product distribution from fast pyrolysis of glucose-based carbohydrates, J. Anal. Appl. Pyrolysis. 86 (2009) 323-330. doi:10.1016/j.jaap.2009.08.007. ChemSusChem. 4 (2011) 1629-1636. doi:10.1002/cssc.201100133.

[8] E.R.E. van der Hage, J.J. Boon, R.J.J.M. Steenvoorden, T.L. Weeding, ResonanceEnhanced Multiphoton Ionization Mass Spectrometric Analysis of Lignin Using Laser Pyrolysis with Entrainment into a Supersonic Jet, Anal. Chem. 66 (1994) 543-550. doi:10.1021/ac00076a020. 
1 [9] S. Karagoz, T. Kawakami, A. Kako, Y. Iiguni, H. Ohtani, Single shot pyrolysis and online conversion of lignocellulosic biomass with HZSM-5 catalyst using tandem microreactor-GC-MS, RSC Adv. 6 (2016) 46108-46115. doi:10.1039/C6RA04225B.

[10] B.S. Kim, Y.M. Kim, J. Jae, C. Watanabe, S. Kim, S.C. Jung, S.C. Kim, Y.K. Park, Pyrolysis and catalytic upgrading of Citrus unshiu peel, Bioresour. Technol. 194 (2015) 312-319. doi:10.1016/j.biortech.2015.07.035.

[11] K. Wang, R.C. Brown, Catalytic pyrolysis of corn dried distillers grains with solubles to produce hydrocarbons, ACS Sustain. Chem. Eng. 2 (2014) 2142-2148. doi: $10.1021 / \mathrm{sc} 5003374$.

[12] a L. Brown, D.C. Dayton, M.R. Nimlos, J.W. Daily, Characterization of biomass pyrolysis vapors with molecular beam, single photon ionization time-of-flight mass spectrometry., Chemosphere. 42 (2001) 663-669.

[13] C.P. Rüger, T. Miersch, T. Schwemer, M. Sklorz, R. Zimmermann, Hyphenation of Thermal Analysis to Ultrahigh-Resolution Mass Spectrometry (Fourier Transform Ion Cyclotron Resonance Mass Spectrometry) Using Atmospheric Pressure Chemical Ionization For Studying Composition and Thermal Degradation of Complex Materials, Anal. Chem. 87 (2015) 6493-6499. doi:10.1021/acs.analchem.5b00785.

[14] J. Sluiter, A. Sluiter, Summative Mass Closure Laboratory Analytical Procedure, NREL/TP-510-48087, National Renewable Energy Laboratory, 2011.

[15] C. Mullen, A. Boateng, Chemical composition of bio-oils produced by fast pyrolysis of two energy crops, Energy and Fuels. 22 (2008) 2104-2109. doi:10.1021/ef700776w.

[16] A. Aho, N. Kumar, K. Eränen, T. Salmi, M. Hupa, D.Y. Murzin, Catalytic pyrolysis of woody biomass in a fluidized bed reactor: Influence of the zeolite structure, Fuel. 87 (2008) 2493-2501. doi:10.1016/j.fuel.2008.02.015.

[17] E.B.M. Hassan, P.H. Steele, L. Ingram, Characterization of fast pyrolysis bio-oils produced from pretreated pine wood, Appl. Biochem. Biotechnol. 154 (2009) 182-192. doi:10.1007/s12010-008-8445-3.

[18] R.B. Cody, A.J. Dane, B. Dawson-Andoh, E.O. Adedipe, K. Nkansah, Rapid classification of White Oak (Quercus alba) and Northern Red Oak (Quercus rubra) by using pyrolysis direct analysis in real time (DART ${ }^{\mathrm{TM}}$ ) and time-of-flight mass spectrometry, J. Anal. Appl. Pyrolysis. 95 (2012) 134-137. doi:10.1016/j.jaap.2012.01.018.

[19] C. Branca, P. Giudicianni, C. Di Blasi, GC/MS characterization of liquids generated from low-temperature pyrolysis of wood, Ind. Eng. Chem. Res. 42 (2003) 3190-3202. doi:10.1021/ie030066d. 
[20] O. Faix, D. Meirer, I. Fortmann, Thermal Degradation Products of Wood, Holz Als Roh Und Werkst. 48 (1990) 351-354.

[21] B. Graham, O.L. Mayol-Bracero, P. Guyon, G.C. Roberts, S. Decesari, M.C. Facchini, P. Artaxo, W. Maenhaut, P. Koll, M.O. Andreae, Water-soluble organic compounds in biomass burning aerosols over Amazonia 1. Characterization by NMR and GC-MS, J. Geophys. Res. Atmos. 107 (2002). doi:10.1029/2001JD000336.

[22] D.C.C. Smith, p-Hydroxybenzoate Groups in the Lignin of Aspen ( Populus tremula )., J. Chem. Soc. (1955) 2347-2351.

[23] R. Sun, X.F. Sun, S.Q. Wang, W. Zhu, X.Y. Wang, Ester and ether linkages between hydroxycinnamic acids and lignins from wheat, rice, rye, and barley straws, maize stems, and fast-growing poplar wood, Ind. Crops Prod. 15 (2002) 179-188. doi:10.1016/S09266690(01)00112-1.

[24] E.D. Christensen, G.M. Chupka, J. Luecke, T. Smurthwaite, T.L. Alleman, K. Iisa, J. a. Franz, D.C. Elliott, R.L. McCormick, Analysis of oxygenated compounds in hydrotreated biomass fast pyrolysis oil distillate fractions, Energy and Fuels. 25 (2011) 5462-5471. doi:10.1021/ef201357h.

[25] J. Adams, Analysis of printing and writing papers by using direct analysis in real time mass spectrometry, Int. J. Mass Spectrom. 301 (2011) 109-126. doi:10.1016/j.ijms.2010.07.025.

[26] M.W. Jarvis, T.J. Haas, B.S. Donohoe, J.W. Daily, K.R. Gaston, W.J. Frederick, M.R. Nimlos, Elucidation of Biomass Pyrolysis Products Using a Laminar Entrained Flow Reactor and Char Particle Imaging, Energy \& Fuels. 25 (2011) 324-336. doi:Doi 10.1021/Ef100832d.

[27] D.L. Carpenter, S.P. Deutch, R.J. French, Quantitative Measurement of Biomass Gasifier Tars Using a Molecular-Beam Mass Spectrometer : Comparison with Traditional Impinger Sampling Quantitative Measurement of Biomass Gasifier Tars Using a Molecular-Beam Mass Spectrometer : Comparison with Traditi, 21 (2007) 3036-3043. doi:10.1021/ef070193c.

[28] L. Jia, Y. Le-Brech, B. Shrestha, M.B. Von Frowein, S. Ehlert, G. Mauviel, R. Zimmermann, A. Dufour, Fast Pyrolysis in a Microfluidized Bed Reactor: Effect of Biomass Properties and Operating Conditions on Volatiles Composition as Analyzed by Online Single Photoionization Mass Spectrometry, Energy and Fuels. 29 (2015) 73647374. doi:10.1021/acs.energyfuels.5b01803. 